OPEN ACCESS

International Journal of

Environmental Research and

Public Health

ISSN 1660-4601

www.mdpi.com/journal/ijerph

Article

\title{
Occupational Hazards Education for Nursing Staff through Web-Based Learning
}

Chen-Yin Tung ${ }^{1}$, Chia-Chen Chang ${ }^{1}$, Jin-Lain Ming ${ }^{2}$ and Keh-Ping Chao ${ }^{3{ }_{*}}$

1 Department of Health Promotion and Health Education, College of Education, National Taiwan

Normal University, Taipei 10610, Taiwan; E-Mails: s09144@ntnu.edu.tw (C.-Y.T.);

babalabear@gmail.com (C.-C.C.)

2 Nursing Department, Taipei Veterans General Hospital, Taipei 11217, Taiwan;

E-Mail: jlming@vhgtpe.gov.tw

3 Department of Occupational Safety and Health, College of Public Health, China Medical University, 91 Hsueh-Shih Rd., Taichung 40402, Taiwan

* Author to whom correspondence should be addressed; E-Mail: kpchao@mail.cmu.edu.tw; Tel.: +886-422-053-366 (ext. 6205); Fax: +886-422-070-500.

External Editor: Paul B. Tchounwou

Received: 28 October 2014; in revised form: 3 December 2014 / Accepted: 8 December 2014 /

Published: 12 December 2014

\begin{abstract}
This study aims to explore the efficiency of using online education as an intervention measure to prevent occupational hazards in a clinical nursing setting. The subjects were 320 female nursing staff from two hospitals in Taiwan. The questionnaire results indicated that the subjects primarily experienced human factor occupational hazards, as well as psychological and social hazards. Specifically, $73.1 \%$ and $69.8 \%$ of the subjects suffered from poor sleep quality and low back pain, respectively. After web-based learning, the experimental group had higher post-test scores than the control group in terms of knowledge, attitudes, and practices (KAP). However, there was only a significant difference $(p<0.05)$ in their knowledge about the prevention of occupational hazards. It is suggested that an online discussion may enhance nursing staff's participation in web-based learning, and further facilitate their comments on negative factors. The findings can highly promote nursing staff's attitudes and practices toward preventing occupational hazards through web-based learning.
\end{abstract}


Keywords: online education; occupational hazard; KAP; hospital

\section{Introduction}

As the workplace for medical treatment and health improvement, hospitals have high standards for safety and hygiene. However, healthcare workers are confronted by numerous occupational hazards due to the unique nature of their work [1]. The convenience of accessing medical information may cause the healthcare workers to neglect the health risks in their workplaces. According to a national survey on occupational hazards in the United States, the incidence rate of occupational injury and illness for the medical and healthcare industry was as high as $6.6 \%$ and ranked forth out of 56 service industries in 2012 [2]. Moreover, compared with workers in other industries, healthcare workers reported more incidents of back strain, dermatitis, infectious hepatitis, infectious diseases, psychological disorders, eye diseases, flu, and toxic hepatitis.

Online learning has been widely applied in the professional training and continuing education for healthcare workers. The benefits of online learning for nursing staff include: (1) the provision of a convenient learning environment that is free from the restrictions of time and space, which is useful for nursing staff who have difficulty attending regular classes; (2) most nursing staff have intermediate to advanced level computer literacy, so that they can easily access online information; and (3) hospitals have well-equipped computers and Internet connections, thus facilitating the promotion of a web-based learning program [3-5]. Chuang and Tsao [3] indicated that online learning by nursing staff could efficiently shorten their learning time, lead to a heightened feeling of achievement, and improve knowledge and skills, thus resulting in a high satisfaction with their courses. Raes et al. [4] found that the efficacy of students' voluntary online learning is equivalent to the conventional classroom teaching. Therefore, it is feasible to develop an online learning program for nursing staff.

According to the Global Information Technology Report, Taiwan is among the top ten countries with complete Internet resources, which include the Internet environment, readiness, usage, and impact [6]. On average, seven out of ten people in Taiwan have Internet-usage experience, and the majority of Internet users have a college degree or higher [7]. For that reason, the intervention of online education is appropriate for the healthcare workers in Taiwan.

In this study, a quasi-experimental design was conducted among 320 female nursing staff at two hospitals in Taipei City, Taiwan. The subjects were divided into an experimental group and a control group. Theories on health behaviors that may influence learners' knowledge, attitudes and practices (KAP) were used to design the teaching materials on occupational safety and health for nursing staff's needs. The experimental group received online education for the prevention of occupational hazards. The purposes of this study were to investigate the efficiency of online education as an intervention measure on preventing occupational hazards, as well as to understand nursing staff's experiences of occupational injuries. The findings can help to promote nursing staff's safety and health in their workplaces. 


\section{Method}

\subsection{Research Subjects}

This study adopted a pre/post-test control group design. The subjects were chosen among nursing staff from two hospitals in Taipei City. Each hospital has approximately 300 beds. One hospital was randomly assigned as the experimental group and the other one was the control group. This study was conducted in accordance with the Declaration of Helsinki, and was approved by the Ethical Committee of the National Taiwan Normal University (IRB approval number P970205). Informed written consent was provided by the subjects prior to their inclusion in this study.

Schumacher et al. [8] found that there were significant gender differences in Internet experiences and attitudes among college students in the United States. Only two and three male nurses worked in the experimental and control hospitals, respectively, so the male nursing staff was excluded from this study. In addition, nursing staff without good experience in using the Internet, i.e., five staff members, were excluded from the experimental group. Finally, a total of 320 full-time nursing staff, including 150 in the experimental group and 170 in the control group, were randomly selected by the administrators from the medical departments in proportion to the total number of nursing staff in each department.

The control group participated in a $4 \mathrm{~h}$ regular education program for occupational safety and health, which was undertaken as the conventional classroom teaching and used the teaching materials developed for web-based learning. Through the website, the experimental group received Internet education for the prevention of occupational hazards over a 6-week period. Head nurses would remind the nursing staff in the experimental group in person or through e-mail to visit the online-learning website.

\subsection{Theoretical Framework}

As shown in Table 1, the content of Internet education for preventing occupational hazards was based on the health behavior theories, such as the health belief model, the persuasive communication model, the social cognitive theory, the social support theory, and the social marketing theory. The health belief model, incorporating the self-efficacy theory, underpinned the theoretical framework of this study. The health belief model suggests that people's beliefs about health problems, perceived benefits of action, and barriers to action explain the engagement in health-promoting behavior [9]. Therefore, understanding and clarifying the positive and negative factors could enhance the nursing staff's knowledge, benefits, and hindrances of preventing occupational hazards. According to the persuasive communication model, Internet-based learning can increase the nursing staff's awareness of occupational hazards by enhancing their motivation to visit the website. Additionally, the framework of this study was grounded in social cognitive theory and social support theory. Interventions based on these theories, such as setting goals for the prevention of occupational hazards, recording details of hazards, and sending e-mail to remind the participation, could promote the nursing staff's attitudes and practices towards the prevention of occupational hazards. 
Table 1. Theoretical framework of the website for the prevention of occupational hazards.

\begin{tabular}{|c|c|c|}
\hline Educational Objective & Educational Theory & Intervention Variable \\
\hline $\begin{array}{l}\text { - Enhance the subjects' motivation to } \\
\text { visit the website }\end{array}$ & $\begin{array}{l}\text { - Persuasive } \\
\text { communication model }\end{array}$ & - Awareness of occupational hazards \\
\hline $\begin{array}{l}\text { - Set goals for the prevention of } \\
\text { occupational hazards and record } \\
\text { details of hazards }\end{array}$ & - Social cognitive theory & $\begin{array}{l}\text { - Attitudes towards the prevention of } \\
\text { occupational hazards }\end{array}$ \\
\hline & & - Knowledge of occupational hazards \\
\hline $\begin{array}{l}\text { - Understand relevant information } \\
\text { concerning the prevention of } \\
\text { occupational hazards }\end{array}$ & - Health belief model & $\begin{array}{l}\text { - Benefits of preventing occupational } \\
\text { hazards } \\
\text { - Hindrances to the prevention of } \\
\text { occupational hazards }\end{array}$ \\
\hline $\begin{array}{l}\text { - Clarify positive and negative } \\
\text { factors for the prevention of } \\
\text { occupational hazards }\end{array}$ & - Health belief model & $\begin{array}{l}\text { - Benefits of preventing occupational } \\
\text { hazards } \\
\text { - Hindrances to the prevention of } \\
\text { occupational hazards }\end{array}$ \\
\hline $\begin{array}{l}\text { - Use online games to simulate } \\
\text { practices for the prevention of } \\
\text { occupational hazards }\end{array}$ & - Self-efficacy & - Practices to prevent occupational hazards \\
\hline $\begin{array}{l}\text { - Use successful examples to enhance } \\
\text { colleagues' confidence }\end{array}$ & - Social support theory & $\begin{array}{l}\text { - Social support to the prevention of } \\
\text { occupational hazards } \\
\text { - Practices to prevent occupational hazards } \\
\text { - Attitudes towards preventing }\end{array}$ \\
\hline $\begin{array}{l}\text { - Use e-mail remainders to reinforce } \\
\text { the participation }\end{array}$ & - Social support theory & $\begin{array}{l}\text { - Soccial support for the prevention of } \\
\text { occupational hazards }\end{array}$ \\
\hline $\begin{array}{l}\text { - Give out complimentary gifts to } \\
\text { attract subjects to visit the website }\end{array}$ & $\begin{array}{l}\text { - Social marketing } \\
\text { theory }\end{array}$ & $\begin{array}{l}\text { - Attitudes towards the prevention of } \\
\text { occupational hazards }\end{array}$ \\
\hline
\end{tabular}

The website content included descriptions of the types of occupational hazards, five online videos and numerous photos that demonstrated the practices to prevent occupational hazards, a blog to share experiences related to occupational hazards, five interactive games, and the website click rate chart. The online teaching materials were reviewed by seven experts, whose professional backgrounds included occupational health, nursing practice, and health education, to ensure that they met the educational objectives shown in Table 1. In addition, the website content was assessed by the head nurses in the experimental hospital. The comments from the experts and head nurses were used to modify the website content.

\subsection{Pre- and Post-Test}

The questionnaires were designed to collect information on individual characteristics (age, level of education), work conditions (workplace, duration of work at the current position, nature of shift work, daily workload, etc.), and perceived experiences of occupational hazards. In addition, the pre-test and post-test encompassed the subjects' awareness, KAP, comments on positive factor, comments on negative factor, self-efficacy and social support toward the prevention of occupational hazards. The experimental and control groups used the same questionnaires for the pre- and post-test, which included 121 closed-ended questions. Respondents were asked to decide where they fit along a scale 
continuum based on the questions from different categories. The questions pertaining to knowledge and social support were answered with a simple "Yes" (1) or "No" (2). The questions pertaining to awareness, self-efficacy, attitudes, and positive/negative comments were rated by the subordinates on a 5-point scale ranging from "Strongly disagree" (1) to "Strongly agree" (5) based on the Likert scale. For the questions of practices, an ordered set of answers was rated on a 7-point scale ranging from "Never" (1) to "Always" (7). For example, the ordinal scale was 1-7 in the response to a question such as "I always wear protective gloves when working." The questionnaire for the subjects' experiences of occupational hazards had a multiple-choice format and was conducted along with the pre-test.

The reliability and validity of the questionnaire were confirmed. The degree of discrimination for each item on the knowledge toward the prevention of occupational hazards was between 0.19 and 0.67 , while the degree of difficulty was between 0.35 and 0.91 . The Cronbach's coefficient alphas for other variables were between 0.7 and 0.95 , indicating that the internal consistency reliability was high. The subjects completed the pre-test and the questionnaire pertaining to their experiences of occupational hazards one week prior to the commencement of the six-week Internet education program. The post-test was carried out one week after program completion.

\subsection{Data Analysis}

The data were analyzed using the Statistical Package for Social Sciences (SPSS) version 19.0. The descriptive statistics and inferential statistical methods were used according to the research purposes. Descriptive statistics indicated the frequency distribution and percentage of the nursing staff's background and experiences of occupational hazards. The chi-square test and paired $t$-test were employed to examine the consistency in nominal variables and interval variables, respectively, for the experimental group and the control group. To perform analysis of covariance (ANCOVA), the pre-test score of each variable was designated as the covariance, and each group was the independent variable to understand the effects of educational intervention on the dependent variables of the subjects.

\section{Results and Discussion}

\subsection{Background}

Table 2 shows the description of individual characteristics of the subjects. The independent $t$-tests and chi-squared tests showed no significant differences between the experimental group and control group on the characteristics, except for the duration of work at the current position $(p<0.05)$. The average work duration of the nursing staff in the experimental group was 4.67 years, while that of those in the control group was 3.57 years. In addition, their experiences in nursing work ranged from 0.5 to 32.5 years, with an average of 7.8 and 6.34 years for the experimental group and control group, respectively. The common educational level was junior college or higher. The nursing staff in the experimental and control groups cared for 4 to 7 patients during an $8-9 \mathrm{~h}$ shift. Moreover, $87.4 \%$ of the subjects in the experimental group and $86 \%$ in the control group had to work on varying shifts. It was difficult for them to attend regular classes on occupational safety and health. 
Table 2. Basic information of the subjects.

\begin{tabular}{|c|c|c|c|c|}
\hline Item & Experimental Group & Control Group & $X^{2}$ & $\mathbf{T}$ \\
\hline Age & 29.04 & 27.93 & & 2.08 \\
\hline Education level (\%) & & & 0.92 & \\
\hline Junior college & 35.7 & 38.8 & & \\
\hline Bachelor degree & 61.1 & 60.0 & & \\
\hline Master degree & 3.2 & 1.2 & & \\
\hline Performing administrative duty (\%) & & & 1.63 & \\
\hline Yes & 5.6 & 6.7 & & \\
\hline No & 94.4 & 93.3 & & \\
\hline Years of experience for nursing work & 7.80 & 6.34 & & 1.54 \\
\hline Years of experience at the current position & 4.67 & 3.57 & & $9.00 *$ \\
\hline Workplace $(\%)$ & & & 4.07 & \\
\hline General medical wards & 41.6 & 35.9 & & \\
\hline Intensive care units & 10.4 & 9.5 & & \\
\hline Operation rooms & 11.5 & 15.5 & & \\
\hline Others (delivery rooms, emergency rooms) & 36.5 & 39.1 & & \\
\hline Nature of shift work (\%) & & & 0.45 & \\
\hline Fixed day shift & 10.5 & 12.8 & & \\
\hline Fixed evening shift & 2.1 & 1.2 & & \\
\hline Fixed night shift & 0.0 & 0.0 & & \\
\hline A rotating shift schedule & 87.4 & 86.0 & & \\
\hline Daily workload (hour/day) & 8.43 & 8.53 & & 0.00 \\
\hline Days of monthly leaves (day/month) & 8.00 & 8.10 & & 0.55 \\
\hline Number of patients per working day (capita/day) & 5.10 & 4.80 & & 0.69 \\
\hline
\end{tabular}

Note: * $p<0.05$.

\subsection{Experiences of Occupational Hazards}

Table 3 shows the subjects' experiences of occupational hazards. The frequency distribution of their experiences of occupational hazards was in a descending order of: human factor hazards > psychological and social hazards $>$ chemical hazards $>$ infectious and biological hazards $>$ physical hazards. Several researchers indicated that the main occupational risks for healthcare workers have changed from chemical, physical, and biological hazards to human factor, as well as psychological and social hazards $[10,11]$. As shown in Table 3, 69.8\% of the nursing staff had experiences of low back pain. Feng et al. [12] found that $66 \%$ of nursing staff in Taiwan were troubled by low back pain due to poor posture and repetitive activities at work over a long time. In addition, Table 3 shows that $60.4 \%$ and $61 \%$ of the subjects had experiences of varicose veins and muscle strains, respectively.

In terms of psychological and social hazards, over $60 \%$ of the subjects reported being in a bad mood (65.9\%), feeling anxious (65.4\%), and having reduced social activities $(65.4 \%)$. Because over $86 \%$ of the subjects had to work on shifts, it is plausible that $73.1 \%$ of the nursing staff reported being troubled by poor sleep quality. As shown in Table 3, 22\% of the subjects had the experience of medical disputes. During the past decades, the number of cases involving medical disputes has increased dramatically in several countries, such as the UK, the USA, Australia, New Zealand, Japan and Taiwan [13]. 
Table 3. Research subjects' experiences of occupational hazards.

\begin{tabular}{lccc}
\hline Types of Hazards & $\mathbf{N}^{\dagger}(\mathbf{\%})$ & Types of Hazards & $\mathbf{N}^{\dagger}(\mathbf{\%})$ \\
\hline Chemical hazards & & Infectious and biological hazards \\
Vertigo and nausea & $78(42.9)$ & Upper respiratory tract infection & $74(40.7)$ \\
Irritated eyes & $68(37.4)$ & Scabies & $17(9.3)$ \\
Respiratory allergy & $59(32.4)$ & Fungal infection & $9(4.9)$ \\
Throat discomfort & $57(31.3)$ & Infectious hepatitis & $9(4.9)$ \\
Occupational dermatitis & $35(19.2)$ & Tuberculosis \\
Kidney and liver Discomfort & $11(6.0)$ & Physical hazards & $4(2.2)$ \\
Nervous system damage & $8(4.4)$ & Burns and scalds & $24(13.2)$ \\
Malicious tumour & $1(0.5)$ & Skin redness \\
Psychological and social hazards & & Reduced white blood cell count & $12(6.6)$ \\
Poor sleep quality & $133(73.1)$ & Malicious tumor & $2(1.1)$ \\
Bad mood & $120(65.9)$ & Human factor hazards & \\
Anxiety & $119(65.4)$ & Low back pain & $127(69.8)$ \\
Reduced social activities & $119(65.4)$ & Muscle strain & $111(61.0)$ \\
Medical dispute & $40(22.0)$ & Varicose veins & $110(60.4)$ \\
Physical violence & $31(17.0)$ & Eye fatigue and harm to eyesight & $99(54.4)$ \\
Sexual harassment & $31(17.0)$ & Falling on the floor & $59(32.4)$ \\
\hline
\end{tabular}

Medical disputes can result in work-related stress for nursing staff. If work stress is not dealt with properly, it could lead to mental exhaustion and physical effects. According to the studies of questionnaires, Chen et al. [11] found that the prevalence rates of physical violence varied from 5.3\% to $21 \%$ in England, Hong Kong and China. Table 3 indicates that $17 \%$ of the subjects reported having experienced physical violence and sexual harassment in the workplace. Even though the frequency distribution of subjects' experiences of physical violence was not significantly high in comparison with other occupational hazards, it is suggested that education in occupational hazards prevention should focus on reducing workplace violence.

\subsection{Participation in Internet Education}

The education website designed by this study could record the number of visits by each subject. Although the head nurses weekly reminded the nursing staff in the experimental group, the records indicated only 115 (76.7\%) of the 150 subjects visited the website with an average of 2.65 times. Among all articles on the website, the articles related to workaholism were most visited, i.e., 46 times. Finally, a total of $91(60.7 \%)$ subjects in the experimental group completed the web-based learning program. In a survey on distance education, Tao and Yeh [14] found that approximately $20 \%-50 \%$ of learners discontinued their learning during the course, for reasons such as lack of time for learning, lack of motivation to learn, having no problem-solving skills, having no peer support, or a poor curriculum design. Kirkley and Stein [15] indicated that the fear of having new job duties added to their heavy clinical workloads is a possible reason behind nursing staff's reluctance to participate in computer and web-based activities. Cheng et al. [16] pointed out that a learner without reasonable motivation is quite difficult to learn online actively. Therefore, there is a need to develop an 
organizational learning environment, such as policies and group enrollment, to increase the nursing staff's motivation to use web-based learning.

\subsection{Effects of Online Education Intervention}

Table 4 shows that the post-test scores of the experimental group were higher than those of the control group. By controlling the pre-test scores, it was found that the post-test scores of the experimental and control groups were significantly different $(p<0.05)$ in their knowledge, awareness, comments on positive factors, self-efficacy and social supports toward the prevention of occupational hazards. After receiving Internet education, the experimental group, however, did not show significantly higher scores of attitudes, practices, and comments on negative factors than the control group. According to the technology acceptance model (TAM), new technologies can enhance users' perceived ease-of-use and perceived usefulness for a system $[17,18]$. Therefore, the nursing staff in the experimental group received novel Internet education, and their knowledge score was significantly higher $(p<0.001)$ than that of the control group.

Table 4. Research subjects' post-test on prevention of occupational hazards.

\begin{tabular}{|c|c|c|c|c|c|}
\hline \multirow[b]{2}{*}{ Item } & \multicolumn{2}{|c|}{ Post-Test Mean } & \multicolumn{2}{|c|}{ Adjusted Mean } & \multirow{2}{*}{$\begin{array}{c}\text { ANCOVA } \\
\text { F Ratio }\end{array}$} \\
\hline & $\begin{array}{c}\text { Experimental } \\
\text { Group }\end{array}$ & $\begin{array}{c}\text { Control } \\
\text { Group }\end{array}$ & $\begin{array}{c}\text { Experimental } \\
\text { Group }\end{array}$ & $\begin{array}{l}\text { Control } \\
\text { Group }\end{array}$ & \\
\hline Awareness & 124.89 & 117.62 & 125.68 & 116.78 & $6.50 *$ \\
\hline Knowledge & 7.66 & 6.74 & 7.62 & 6.80 & $9.86 * *$ \\
\hline Attitudes & 28.78 & 28.13 & 28.78 & 28.13 & 1.22 \\
\hline Practices & 45.06 & 43.47 & 44.70 & 43.86 & 1.98 \\
\hline Comments on positive factor & 37.04 & 35.40 & 36.97 & 35.49 & $4.58 *$ \\
\hline Comments on negative factor & 30.76 & 30.56 & 30.95 & 30.34 & 0.84 \\
\hline Self-efficacy & 21.51 & 19.96 & 21.36 & 20.14 & $4.92 *$ \\
\hline Social support & 5.21 & 4.52 & 5.15 & 4.59 & $6.19 *$ \\
\hline
\end{tabular}

Notes: $* p<0.05 ; * * p<0.001$.

Table 5 compares the post-test scores of the subjects' awareness toward the prevention of chemical, physical, infectious, biological, psychological and social hazards, as well as human factors. The experimental group had better performance on the hazard awareness than the control group did. However, the experimental group and the control group showed a significantly statistical difference $(p<0.05)$ only on their awareness toward the infectious and biological hazards. The online videos and photos showed the practical prevention of the needle stick injury. Additionally, there were step-by-step demonstrations of how to use the respiratory protective equipment in the workplace. The nursing staff of the experimental group could repeat web-based learning of teaching videos. Liu [19] found that teaching videos of new issues which feature converted professional knowledge can enhance the learner's performances. Therefore, the visual stimuli of Internet education could help nursing staff in the experimental group to more easily acquire the information on preventing infectious and biological hazards. This can be the reason that the post-test score of the experimental group was significantly higher than that of the control group on the awareness toward infectious and biological hazards. 
Table 5. Analysis of research subjects' awareness toward prevention of occupational hazards.

\begin{tabular}{|c|c|c|c|c|c|}
\hline \multirow[b]{2}{*}{ Types of Hazards } & \multicolumn{2}{|c|}{ Post-Test Mean } & \multicolumn{2}{|c|}{ Adjusted Mean } & \multirow[b]{2}{*}{$\begin{array}{c}\text { ANCOVA } \\
\text { F Ratio }\end{array}$} \\
\hline & $\begin{array}{c}\text { Experimental } \\
\text { Group }\end{array}$ & $\begin{array}{l}\text { Control } \\
\text { Group }\end{array}$ & $\begin{array}{c}\text { Experimental } \\
\text { Group }\end{array}$ & $\begin{array}{l}\text { Control } \\
\text { Group }\end{array}$ & \\
\hline Biological hazards & 26.02 & 24.42 & 26.08 & 24.36 & $4.08 *$ \\
\hline Chemical hazards & 28.95 & 27.53 & 29.07 & 27.40 & 2.63 \\
\hline Physical hazards & 20.80 & 19.61 & 20.69 & 19.72 & 1.33 \\
\hline Human factors hazards & 21.54 & 20.96 & 21.52 & 20.98 & 0.93 \\
\hline Psychological \& social hazards & 26.89 & 25.93 & 27.08 & 25.73 & 0.11 \\
\hline
\end{tabular}

Note: * $p<0.05$.

For the experimental group, the nursing staff received weekly reminders from the head nurses, and shared their experiences of occupational hazards on the website's blog, giving them an opportunity to interact with each other. In addition, the nursing staff could feel the concerns of their colleagues and the hospital on their health. This may result in an effect on their post-test scores on social support and comments on positive factors toward the prevention of occupational hazards. Bandura [20] developed the social cognitive theory and indicated that social support is vital to self-efficacy. Social support from the colleagues and hospital of the experimental group could be positively related to nursing staff's self-efficacy. Therefore, it is plausible that self-efficacy of the post-test for the experimental group was significantly higher than the control group $(p<0.05)$.

\subsection{Attitudes and Practices of Subjects}

As shown in Table 4, the post-test scores of the experimental group on attitudes, practices, and comments on negative factors were higher than those of the control group. However, the difference between these two groups did not show statistical significance. According to the social cognitive theory, Bandura [20] indicated that social support influences behavior through self-efficacy. In addition, Shih [21] found that self-efficacy indirectly affected individuals' behavioral intentions and attitudes toward web-based learning. For the experimental group, the scores of self-efficacy and social support in the post-test were significantly higher than those of the control group $(p<0.05)$. It is speculated that comments on negative factors may play an influential role in nurses' attitudes and practices toward web-based learning for occupational education.

Several studies have found that the discussion through online teaching is a critical dimension of web-based learning to enhance the learners' achievement and satisfaction [22-24]. Cook et al. [24] indicated that the most effective e-learning methods for health professionals are those that include interactivity and feedback. In this study, the blog, created for the experimental subjects to share their experiences of occupational hazards, lacked an online discussion which could provide solutions to the problems that they encountered during the web-based learning program. Therefore, the post-test score of the experimental group was not significantly higher than that of the control group in the comments on negative factors. A lack of an online discussion on the website might further result in a low completion rate $(60.7 \%)$ of online courses for the nursing staff in the experimental group. 


\section{Conclusions}

Among the 320 female nursing staff participated in this study, most of them experienced occupational hazards due to human factor as well as psychological and social hazards. Moreover, $73.1 \%$ and $69.8 \%$ of them had the experiences of poor sleep quality and lower back pain, respectively. After completing the web-based learning program, the subjects of the experimental group had higher post-test scores than those of the control group. However, the experimental group and the control group did not show significant differences in their attitudes and practices toward the prevention of occupational hazards. A possible explanation for this result may be that the education website lacked an online discussion forum which could offer solutions to the problems encountered by the nursing staff in the prevention of occupational hazards. In addition, the lack of an online discussion may result in a low completion rate of the web-based learning program. Hence, setting up an online discussion forum for the education website may facilitate nursing staff's comments on negative factors, which can raise their motivation to complete the learning program. This effort will stimulate nursing staff's attitudes and practices toward the prevention of occupational hazards in hospitals.

\section{Acknowledgments}

The study was supported by the National Science Council, Taiwan, ROC (NSC94-2516-S-003-009).

\section{Author Contributions}

Chen-Yin Tung was responsible for the original idea, concept, organization, and financing of the study. Keh-Ping Chao developed the study design, and wrote the manuscript and final version of the illustrations. Chia-Chen Chang and Jin-Lain Ming performed the pre-test, post-test and statistical analyses. All authors read and approved the final manuscript.

\section{Conflicts of Interest}

The authors declare no conflict of interest.

\section{References}

1. Chiou, S.T.; Chiang, J.H.; Huang, N.; Wu, C.H.; Chien, L.Y. Health issues among nurses in Taiwanese hospitals: National survey. Int. J. Nurs. Stud. 2013, 50, 1377-1384.

2. Occupational Injuries and Illnesses in the United States by Industry; United States Bureau of Labor Statistics: Washington, DC, USA, 2012.

3. Chuang, Y.H.; Tsao, C.W. Enhancing nursing students' medication knowledge: The effect of learning materials delivered by short message service. Comput. Educ. 2013, 61, 168-175.

4. Raes, A.; Schellens, T.; de Wever, B.; Vanderhoven, E. Scaffolding information problem solving in web-based collaborative inquiry learning. Comput. Educ. 2012, 59, 82-94.

5. Liang, J.C.; Wu, S.H.; Tsai, C.C. Nurses' Internet self-efficacy and attitudes toward web-based continuing learning. Nurs. Educ. Today 2011, 31, 768-773. 
6. World Economic Forum. Global Information Technology Report 2013. Available online: http://www.weforum.org/reports/global-information-technology-report-2013 (accessed on 30 September 2014).

7. Taiwan Network Information Center. Available online: http://statistics.twnic.net.tw/query/surveyquery.cgi (accessed on 30 September 2014).

8. Schumacher, P.; Morahan-Martin, J. Gender, Internet and computer attitudes and experiences. Comput. Human. Behav. 2001, 17, 95-110.

9. Rosenstock, L.M.; Strecher, V.J.; Becker, M.H. Social learning theory and the Health Belief Model. Health Educ. Quart. 1988, 15, 175-183.

10. Khamisa, N.; Peltzer, K.; Oldenburg, B. Burnout in relation to specific contributing factors and health outcomes among nurses: A systematic review. Int. J. Environ. Res. Public Health 2013, 10, 2214-2240.

11. Chen, W.C.; Sun, Y.H.; Lan, T.H.; Chiu, H.J. Incidence and risk factors of workplace violence on nursing staffs caring for chronic psychiatric patients in Taiwan. Int. J. Environ. Res. Public Health 2009, 6, 2812-2821.

12. Feng, C.; Chen, M.L.; Mao, I.F. Prevalence of and risk factors for different measures of low back pain among female nursing aides in Taiwanese nursing homes. BMC Musculoskelet. Disord. 2007, 8, doi:10.1186/1471-2474-8-52

13. Wu, C.Y.; Weng, H.C.; Chen, R.C. Time trends of assessments for medical dispute cases in Taiwan: A 20-year nationwide study. Intern. Med. J. 2013, 43, 1023-1030.

14. Tao, Y.H.; Yeh, C.C.R. Typology of teacher perception toward distance education issues-A study of college information department teachers in Taiwan. Comput. Educ. 2008, 50, 23-26.

15. Kirkley, D.; Stein, M. Nurses and clinical technology: Sources of resistance and strategies for acceptance. Nurs. Econ. 2004, 22, 216-222.

16. Cheng, B.; Wang, M.; Moormann, J.; Olaniran, B.A.; Chen, N.S. The effects of organizational learning environment factors on e-learning acceptance. Comput. Educ. 2012, 58, 885-899.

17. Chen, I.J.; Yang, K.F.; Tang, F.I.; Huang, C.H.; Yu, S. Applying the technology acceptance model to explore public health nurses' intentions towards web-based learning: A cross-sectional questionnaire survey. Int. J. Nurs. Stud. 2008, 45, 869-878.

18. Davis, F.D. User acceptance of information technology: System characteristics, user perceptions, and behavioral impacts. Int. J. Man Mach. Stud. 1993, 38, 475-487.

19. Liu, M.H. Discussing teaching videocases online: Perspectives of preservice and inservice EFL teachers in Taiwan. Comput. Educ. 2012, 59, 120-133.

20. Bandura, A. Self-efficacy: The Exercise of Control; Worth Publishers: New York, NY, USA, 1997.

21. Shih, H.P. Using a cognition-motivation-control view to assess the adoption intention for Web-based learning. Comput. Educ. 2008, 50, 327-337.

22. Loncar, M.; Barrett, N.E.; Lin, G.Z. Towards the refinement of forum and asynchronous online discussion in educational contexts worldwide: Trends and investigative approaches within a dominant research paradigm. Comput. Educ. 2014, 73, 93-110.

23. Andresen, M.A. Asynchronous discussion forums: Success factors, outcomes, assessments, and limitations. J. Educ. Technol. Soc. 2009, 12, 249-257. 
24. Cook, D.A.; Levinson, A.; Garside, S.; Dupras, M.; Erwin, P.G.; Montori, V.M. Instructional design variations in internet-based learning for health professions education: A systematic review and meta-analysis. Acad. Med. 2010, 85, 909-922.

(C) 2014 by the authors; licensee MDPI, Basel, Switzerland. This article is an open access article distributed under the terms and conditions of the Creative Commons Attribution license (http://creativecommons.org/licenses/by/4.0/). 